\title{
SMALL PUNCH TEST - TWO METHODS OF TsP TEMPERATURE DETERMINATION
}

\author{
1'̌́árka STEJSKALOVÁ, '1Ladislav KANDER, ${ }^{1}$ Petr ČÍŽEK \\ ${ }^{1}$ Material and metallurgical Research, Ltd., sarka.stejskalova@mmvyzkum.cz,
}

https://doi.org/10.37904/metal.2021.4158

\begin{abstract}
Small punch test is very useful method for evaluation of actual material properties of components especially in power industry. Two standards cover small punch test method - European standard and ASTM standard. These standards unified the main parameters of small punch test set-up and correlation relationships for the evaluation of mechanical, fracture and creep properties. The paper deals with comparison of two methods for determination of TSP temperature used to evaluate DBTT. The historically used two-curve method relies on two distinctive energies - the fracture energy at the zero-point of the absolute temperature, that is determined by extrapolating the fitted function for the lower shelf, and the fracture energy at the intersection point between the fits for the lower and upper shelves. The method preferred by new standards calculates TSP temperature by fitting a tangential function in the similar way as various formulas used for evaluation of Charpy tests. Presented paper deals with an evaluation of Tsp temperature by both methods. The effect of using both $2 \mathrm{~mm}$ and $2.5 \mathrm{~mm}$ diameter punches is assessed too.
\end{abstract}

Keywords: Small punch test, standard for small punch test method, determination of TsP temperature, punch diameter

\section{INTRODUCTION}

The small punch test (SPT) has been established as widely used method for the assessment of the mechanical properties, fracture properties, creep properties and the evaluation of residual lifetime especially in cases, where it is technically difficult or even impossible to obtain enough bulk material for standard tests. This paper focuses on TSP temperature determination that is used to calculate the ductile-brittle transition temperature (DBTT). In 2020 year, two standards cover SPT method were finalized and issued - an European standard on SP testing of metallic materials EN 10371 [1] and ASTM standard E3205-20 (Test method for small punch testing of metallic materials) [2].

Both standards unified the main parameters of SP set up and the correlation equations for determining material properties mentioned above. There are two methods of TSP determination from SPT used in this paper: a twocurve method still commonly used in MMV and evaluation using the tangential function according to European standard. At the same time the article presents a comparison of SPT results obtained using punch with a diameter of $2 \mathrm{~mm}$ and $2.5 \mathrm{~mm}$.

Main changes introduced by the European standard EN 10371 are the use of a $2.5 \mathrm{~mm}$ punch diameter and the use of a tangential function for determination of TsP from SP energy.

\section{THE ESTIMATION OF TSP FROM SP ENERGY}

The small punch test is a very potential method for evaluation residual life time assessment. This method can be used both for evaluation of material properties (yield stress, tensile strength) and transition behaviour (DBTT temperature. Generally, two methods for evaluation of DBTT exist first and older approach is based on two 
curves exponential fitting of small punch test energy $\left(E_{S P}\right)$ second one is based on fitting of normalized fracture energy $\left(E_{n}\right)$ by tanh function.

In order to determine the DBTT by the SPT method, it is essential to determine the TsP temperature value from the SP energy. A linear correlation between SP ductile to brittle transition temperature TsP, and the Charpy transition temperature, DBTT, is given in Formula (1):

$T_{S P}=\alpha *$ DBTT

Where correlation factor $\alpha$ was found to be about 0.43 and depends on material properties, structure and other parameters (grain size). The TsP can be extracted from multiple SP tests at different temperatures. From a single force-displacement/deflection curve the energy $E_{S P}$ is calculated. Doing this for different temperatures, the $E_{S P}(T)$ dependence is constructed and TSP evaluated. The total SP energy is calculated as the area under the force-displacement or force-deflection curve, the calculation takes into account the energy up to the deflection or displacement at maximum force $\mathrm{F}_{\mathrm{m}}$. [1]

\subsection{The determination of $T_{S P}$ using two-curve method}

This method takes into account the separate two parts of the $E_{S P}$ - the lower and upper shelves (see Figure 1), where the lower shelf includes the transition region. In this approach two distinctive energies can be defined: $E_{\min }$, the fracture energy at the zero point of the liquid nitrogen temperature, is determined by extrapolating the fitted function for the lower shelf. $E_{\max }$ is the fracture energy at the intersection point between the fits for the lower and upper shelves. The Tsp temperature is then defined as the temperature where:

$T_{S P}=\left(E_{\min }+E_{\max }\right) / 2$

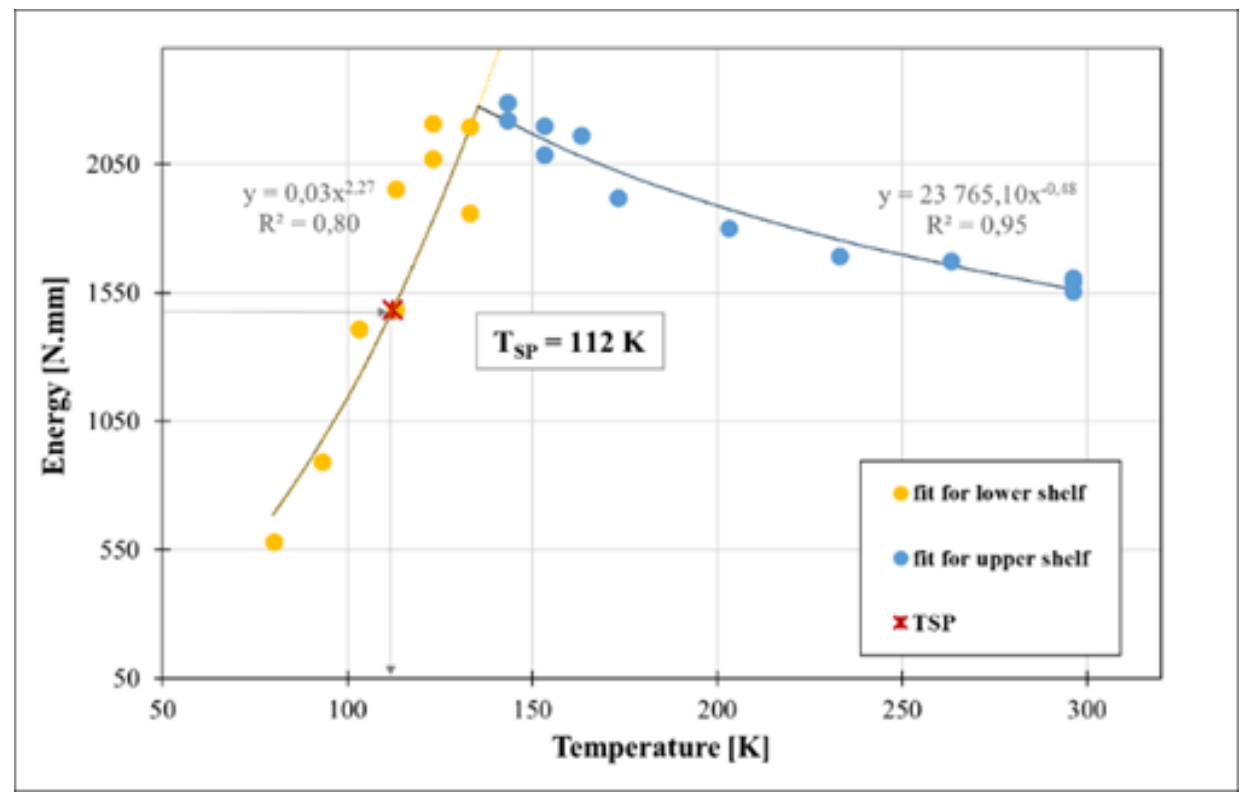

Figure 1 TsP temperature determination using two-curve method

In MMV this method has been used for more than 20 years to evaluate a large amount of data (boiler drums, valves, pipes, turbine shafts and cases, overheaters etc.). During this time, it has been proven to be a reliable method that reflects actual fracture property of steels accurately and sensitively.

\subsection{The determination of $T_{S P}$ using a tangential function}

European standard prefers TSP determination by using of a tangential function. The normalized energy for fitting procedure is defined by Formula (2): 
$E_{n}=E_{S P} / F_{m}$

A tanh-fitting procedure can be applied for the $E_{n}(T)$ dependence. The fitting curve is described by Formula (3) [1]:

$$
E_{\mathrm{n}}(T)=A+B \cdot \tanh \left[\frac{T-T_{\mathrm{SP}}}{C}\right]=\frac{E_{\mathrm{US}}+E_{\mathrm{LS}}}{2}+\frac{E_{\mathrm{US}}-E_{\mathrm{LS}}}{2} \cdot \tanh \left[\frac{T-T_{S P}}{C}\right]
$$

The normalization procedure leads to elimination or significant reduction of the decreasing behaviour of the upper shelf energy since the maximum force is also decreasing with temperature. On the other hand, the constraint correction has to be applied to data as in the most cases negative lower shelf energy $\left(E_{L S}<0\right)$, which is physically nonsense, is identified especially for tough materials. The standard prescribes a minimum of 12 specimens that should be tested to construct dependence. At least three of the specimens should be tested in the range of the upper shelf energy. Figure 2 shows an example of plot for P92 steel.

Advantage of tangential function for $T_{S P}$ evaluation is that the resulting dependence has the same shape as the well-known temperature dependence of the Charpy impact test, so it is familiar to many people. Although some sources state that the evaluation using tangential function is more accurate [3,4], when we processed the data in MMV we came to completely different results as it is stated in chapter 4.

Same experiences were found in VUJE (Slovakia) where only two curves fitting method is used for evaluation of actual properties of irradiated components.

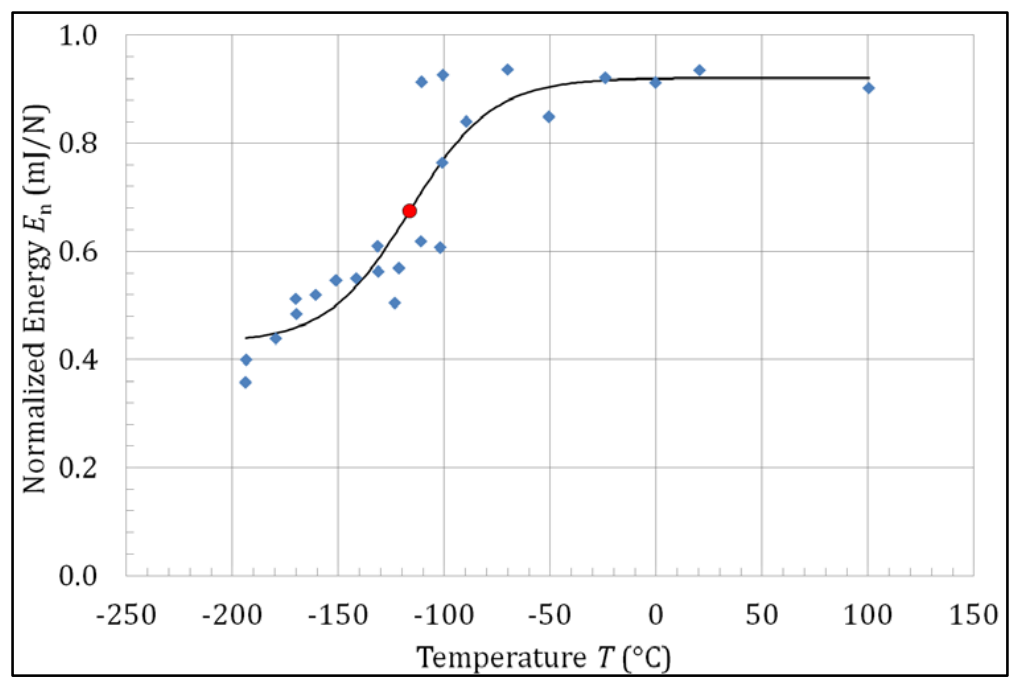

Figure 2 Determination of $\mathrm{TSP}_{\mathrm{SP}}$ using the normalized energy. Steel P92; $\mathrm{TSP}_{\mathrm{SP}}=-116{ }^{\circ} \mathrm{C}$ (red point) [1]

\section{THE USE OF A 2 MM AND 2.5 MM PUNCH DIAMETER}

Historically in MMV SPT was carried out with a $2 \mathrm{~mm}$ punch diameter. Then, when the standards established the use of a $2.5 \mathrm{~mm}$ punch diameter, it was necessary to maintain continuity in the reassessment of individual components. For this reason, we have included SPT evaluation of materials using both $2 \mathrm{~mm}$ and $2.5 \mathrm{~mm}$ diameter punches. These results are shown in chapter 4 too.

\section{RESULTS}

The effect of the method used to evaluate the Tsp temperature and punch diameter is shown in the results for P91 grade. These are steam pipes of P91 grade in as-received conditions (with dimensions $\varnothing 605 \times 35 \mathrm{~mm}$ 
and $\varnothing 116 \times 35 \mathrm{~mm})$ and another one after the exposure $\left(600^{\circ} \mathrm{C} / 7500 \mathrm{~h}\right)$. Then steam pipes of P92 grade $(\varnothing$ $530 \times 90 \mathrm{~mm})$ and another one with increased content of $\mathrm{Cu}(\varnothing 300 \times 25 \mathrm{~mm})$, both of them in as-received condition.

\subsection{Determination of $T_{S P}$ temperature}

Due to the limited extend of this paper, only the results of the P91 pipes are presented. Figure 3 shows the processing of the measured SP energy values using the two-curve method. At the same time, the influence of the punch diameter is also presented in Figure 3.

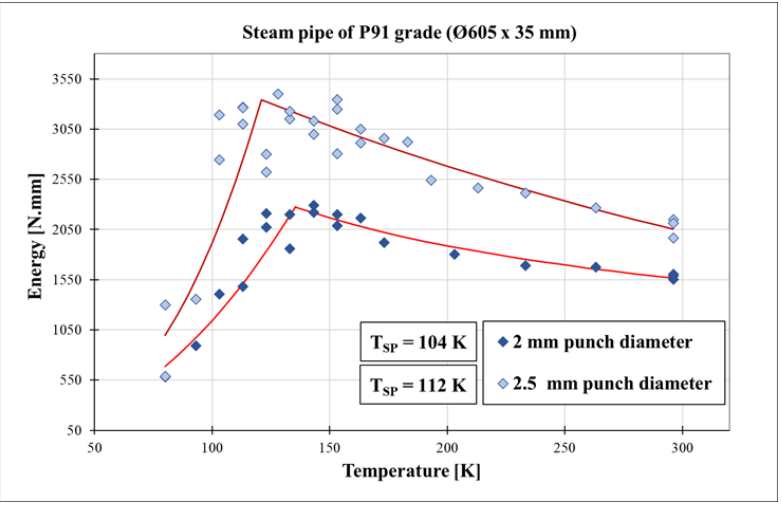

a

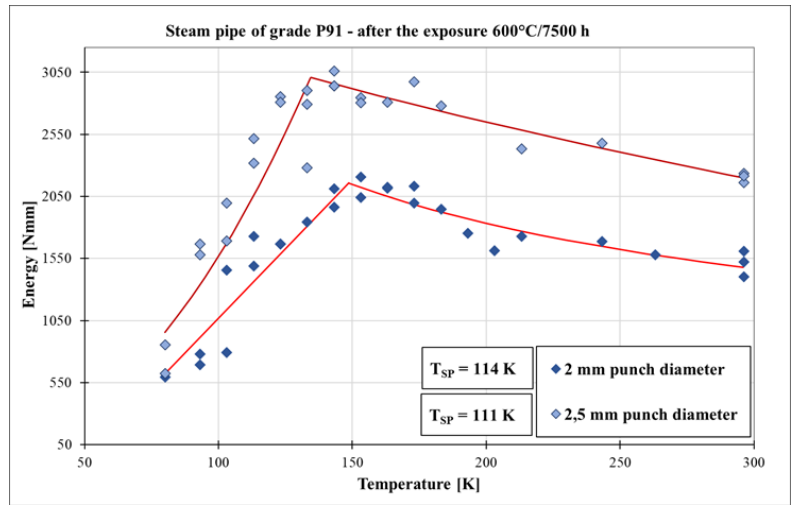

b

Figure 3 Effect of diameter of the puncher on TSP temperature determined from EsP energy using two curve methods for P91 grade steam pipes, as virgin state and after thermal exposure 7500 hours

Figure 4 and Figure 5 show the processing of the normalized energy values using the tangential function using a $2 \mathrm{~mm}$ and $2.5 \mathrm{~mm}$ punch diameter, respectively.

One of the disadvantages of this method appears to be the number and distribution of measured values that the tangential function is fitted with. If there are few points on the lower shelf and all others are closer to the upper shelf, the tangential function cannot be fitted (see Figure 5a). Another point for discussion in using the tangential function is that a minimum value for the lower shelf has to be set manually, which can also significantly affect the resulting $\mathrm{Tsp}$ temperature.

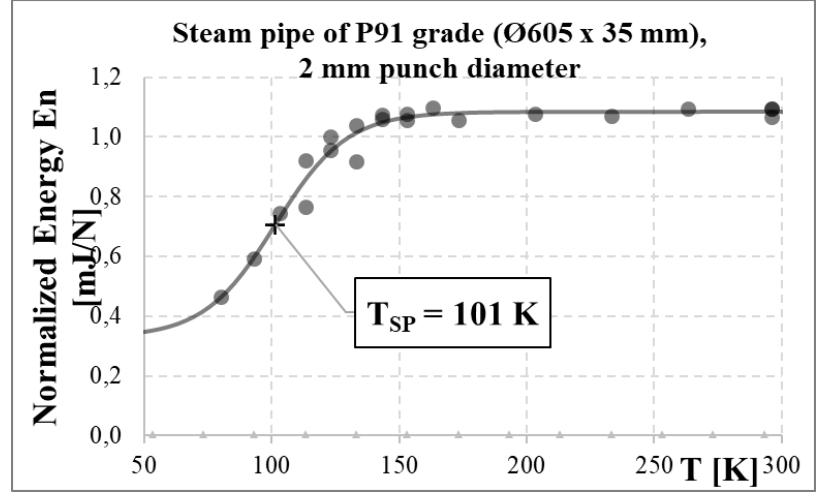

a

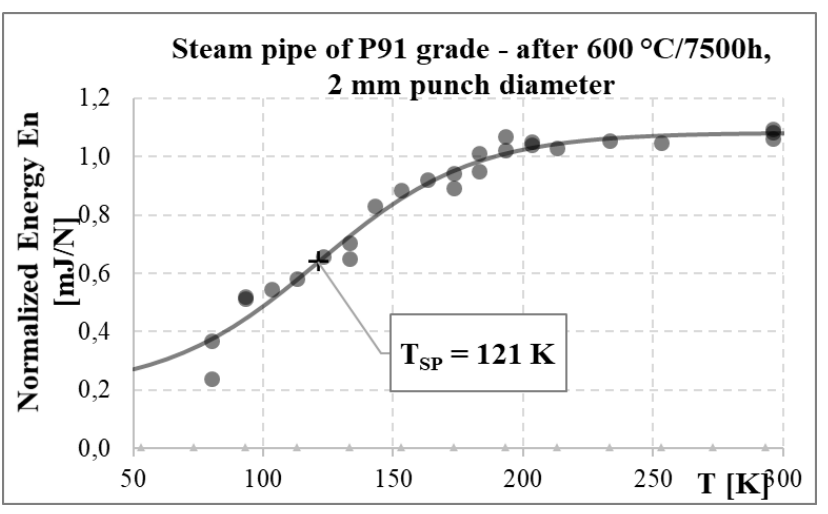

b

Figure 4 Determination of TSP temperature using a tangential function for P91 grade steam pipe - $\mathbf{2 m m}$ punch diameter 


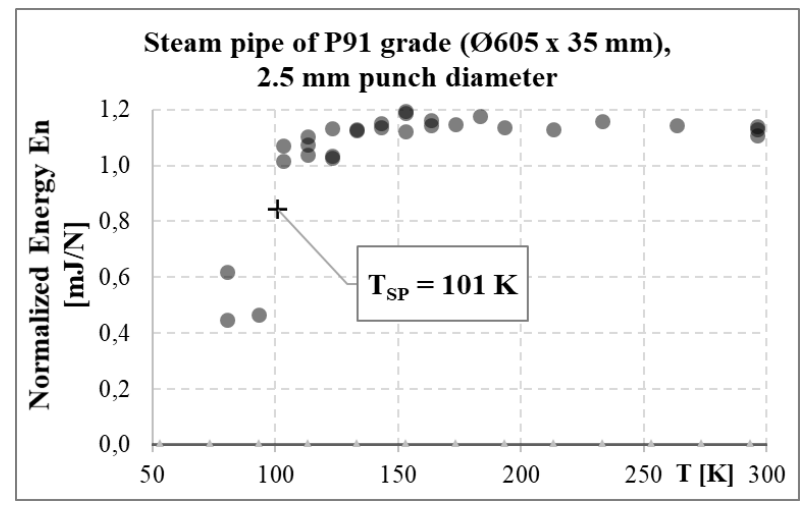

a

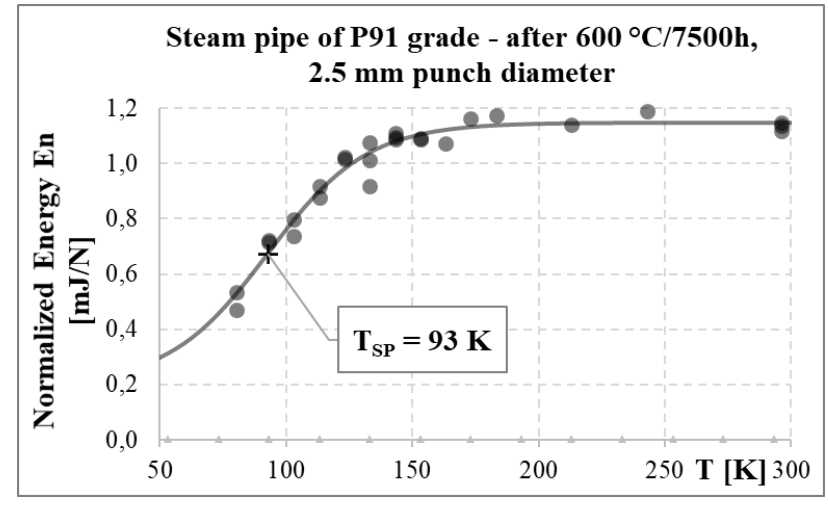

b

Figure 5 Determination of TsP temperature by using a tangential function for P91 grade steam pipe -

\section{$2.5 \mathrm{~mm}$ punch diameter}

A comparison of the TSP temperature values evaluated by the two-curve method and the tangential method using both punches for grades P91 and P92 is shown in Table 1. The determination of the TsP temperature using the tangential function shifted all temperatures to lower, less conservative values compared to the results of the two-curve method. Since the TSP temperature is used to calculate the DBTT, this fact is quite problematic.

Table $1 \mathrm{~T}_{\mathrm{SP}}$ temperature determined using two curves method and tangential function for steam pipes of P91 and P92 grade

\begin{tabular}{|c|c|c|c|c|}
\hline \multirow[b]{2}{*}{ punch diameter } & \multicolumn{2}{|c|}{ TsP - two curve method [K] } & \multicolumn{2}{|c|}{ TSP - tangent function [K] } \\
\hline & $2 \mathrm{~mm}$ & $2.5 \mathrm{~mm}$ & $2 \mathrm{~mm}$ & $2.5 \mathrm{~mm}$ \\
\hline P91 Ø 605 x 35 mm & 104 & 112 & 101 & $(101)$ \\
\hline P91 Ø 116 x 35 mm & 114 & 96 & 93 & 88 \\
\hline P91 after $600^{\circ} \mathrm{C} / 7500 \mathrm{~h}$ & 114 & 111 & 121 & 93 \\
\hline P92_90_I & 130 & 128 & 136 & 105 \\
\hline P92 after $650{ }^{\circ} \mathrm{C} / 7500 \mathrm{~h}$ & 129 & 114 & 130 & 98 \\
\hline $\mathrm{P} 92+\mathrm{Cu}$ & 139 & 121 & 146 & 119 \\
\hline
\end{tabular}

Based on long-term practical experience and a large amount of measured data in MMV (hundreds of components), it can be concluded that the evaluation of TSP temperature by the two-curve method responds very well to changes in material actual properties as well as this approach more sensitive show various effect of metallurgical parameters on fracture behaviour [5].

On the other hand, various metallurgical effects (aging, heat treatment etc.) are indistinct when using new tanh fitting. This fact can be seen in Table 1 and it is clearer for $2.5 \mathrm{~mm}$ puncher diameter. Similar evaluation has been carried out for historical results collected in last two decades with the same result - using tanh fitting less conservative results in TSP were obtained.

\section{CONCLUSION}

In terms of presented experimental work based on a lot of experimental data evaluated in the last two decades we can conclude following results:

- $\quad$ There are two approaches for evaluation of transition DBTT temperature from SP tests, one is based on two exponential curves second and preferred in new standards is base on tanh function. As the tanh function seems to be user more friendly as this shape is already used for Vidal curve experimental results clearly seen nonconservative evaluation by this way. Even sensitivity for various metallurgical 
factors (aging, heat treatment) is less compare to the results from two curve exponential fitting [5]. This fact is clearly seen especially for $2.5 \mathrm{~mm}$ puncher diameter on Table 1, where only a few components - transition temperatures are presented.

- In the case of tough materials, usually used in power industry, the normalization procedure needs the constraint correction as in the most cases negative lower shelf energy ( $\left.E_{L S}<0\right)$, which is physically nonsense, is identified. When using the tangential function, a minimum value for the lower shelf has to be set manually, which can also affect the resulting $T_{S P}$ temperature significantly.

\section{ACKNOWLEDGEMENTS}

This paper was created in the Project No. TK010201603 "Complex procedures of material engineering to ensure the safe operation of innovated blocks of fossil power plants." funded by the Technology Agency of The Czech Republic (TACR)

„This paper was created as part of the drawing and use of institutional support for Long-term and conceptual development of a research organization in 2021, provided by the Ministry of Industry and Trade of the Czech Republic".

\section{REFERENCES}

[1] CEN - EN 10371 - Metallic materials - Small punch test method, CEN, 2021.

[2] ASTM E3205 - 20: Small Punch Testing of Metallic Materials, West Conshohocken, PA 19428-2959. United States, ASTM International 2020.

[3] BERGNER, F., HOUSKA, M. Use of small punch test for the estimation of ductile-to-brittle transition temperature shift of irradiated steel. Nuclear Materuials and Energy. [online]. January 2021, p. 9. Available from: https://doi.org/ 10.1016/j.nme.2021.100918.

[4] BRUCHHAUSEN, M., HOLMSTRÖM, S., LAPETITE, J.-M., RIPPLIMGER, S. On the determination of the Ductile to Brittle Transition Temperature from Small punch tests on Grade 91 ferritic-martensitic steel. International Journal of Pressure Vessels and Piping. [online]. 2017, p. 11. Available from: https://doi.org/ 10.1016/j.ijpvp.2017.06.008.

[5] STEJSKALOVÁ, Š. Assessment of actual material properties of deasphalting tower in Normandy refinery using small punch test method. Technical report T8/2021. Ostrava: Materiálový a metalurgický výzkum, 2021. 